\title{
Introduction: Hybrid journalism? Making sense of the field's dissolving boundaries
}

Colin Porlezza*, City, University of London, Department of Journalism, United Kingdom Philip Di Salvo, Università della Svizzera italiana (USI), Institute of Media and Journalism, Switzerland

*Corresponding author: Colin.Porlezza@city.ac.uk

In the last couple of years, hybridity has become a buzzword in journalism studies. Hybridity has often been used to describe ongoing transformations in journalism. In this sense, the increasing use of hybridity in the discipline can be seen as an answer, as Witschge, Anderson, Domingo and Hermida (2019, p. 652) declare, "to rising complexity in both journalism practice and scholarship". At the same time, however, the use of the concept has itself become an object of scholarly debate: while some reject the notion as an undercomplex "catch-all" concept, others believe in its heuristic and analytical prowess. This debate is reinforced by the multiple connotations attributed to the notion, and how the term is used in positive ("a capacity for growth”; Stross, 1999, p. 257) or negative ("diluted version of [the] antecedents"; Chadwick, 2013, p. 14) senses. Either way, hybridity's success in journalism studies certainly reflects an emancipation from conventional journalism theory, and as a call to develop "new conceptualizations, terminology, and vocabulary" (Witschge et al., 2019, p. 652) in order to grasp the current transformations in journalism and the different forms of journalism that go beyond traditional understandings and definitions of journalism.

The proliferation of the hybridity notion within journalism studies is also mirrored by the different academic events and scholarly publications. There were several symposia dealing with the topic, for instance the ECREA pre-conference entitled "Dissolving Boundaries of Hybrid Journalism", which was held at the Università della Svizzera italiana in Lugano, Switzerland, on October $31^{\text {st }} 2018$. This Themat- ic Section contains a selection of papers presented at this specific pre-conference, where Adrienne Russell (University of Washington, USA) was the keynote speaker. In addition to such specific events, hybridity has also been discussed in a special issue of the scholarly journal "Journalism" (Mast, Coesemanns, \& Temmermann, 2017). Moreover, several articles (e.g., Deuze \& Witschge, 2018; Mellado et al., 2017; Papacharissi, 2015; Ruotsalainen, Hujanen, \& Villi, 2019; Witschge et al., 2019) as well as books (e.g., Chadwick, 2013; Deuze \& Witschge, 2020) have been published that discussed the topic from many different perspectives and contributed significantly to push the concept to the core of scholarly debates.

The concept of hybridity understands journalism as part of a wider network, in which different fields, actors, genres, and values come together, blend, and affect each other (Chadwick, 2013; Witschge et al., 2019). In addition, the datafication of journalism - the fact that journalism is increasingly produced by different actors with different backgrounds, intentions and norms such as hackers, activists or even by artificial intelligence-led tools shows that journalism often transcends traditional conceptions of journalism. Speaking with Latour (1993), hybridity can help us to place journalism in a larger socio-technical environment and to better understand how new and complex patterns are formed. However, there are several open questions with regard to the concept of hybridity and to its use in journalism research, which led Baym (2017) to conclude that hybridity is an under-researched and under-explored topic. 
First, is the concept heuristically and analytically robust enough to be applied in the investigation of ongoing changes in journalism? As Witschge et al. (2019, p. 654) state, we need to evaluate hybridity's "explanatory value and take the next step to not only name but also describe and theorize the complexity of the field" of journalism. Hybridity entails the risk that it can be used as a shortcut to describe and analyze convoluted transformations in news production, distribution, and consumption. As a consequence, the same authors who proposed hybridity as a viable analytical concept, later on calling to deal "with the mess we made" (Witschge et al., 2019). Instead, they suggested to go beyond hybridity and to understand it not as a simple absence of order, as a chaotic mashup of different things, but rather as a dynamic order that is more liquid, fragile, and unstable, and thus more in line with how journalism actually presents itself today. Nevertheless, the main goal is to understand "how that order is constructed, given the complex set of relations in any given context" (Witschge et al., 2019, p. 656). Hybridity can thus be understood as a viable starting point to overcome a simple "either/or" thinking (Chadwick, 2013 , p. 4), and allows us to move more closely towards a "both" option.

Second, even if we argue that the main advantage of the concept of hybridity is to allow us to move beyond simplistic and dichotomic notions of what journalism is and what it is not, approaching hybridity as "a particularly rich site for the analysis of forms and processes of experimentation, innovation, deviation and transition in contemporary journalism" (Mast et al., 2017 , p. 3) would alter it into a one-sizefits-all concept used to explain what we are unable to grasp. Nonetheless, the "hybrid turn" was a refreshing - and necessary transformation in the way journalism scholars understood journalism, which in the past has far too often focused "on a stabilized and homogeneous understanding of the field" (Witschge et al., 2019, p. 652). As the journalism field changes not only at its peripheries, but increasingly also at its core, the concept of hybridity is able to push the field forward. As Zelizer (2009, p. 1) wrote way before the hybridity concept became widely used in journalism studies, news and journalism have always been "multiple, multi-dimensional, multi-directional and multi-faceted". Hybridity is thus able to depict "the development of journalism towards a networked, de-bounded and de-institutionalized future" (Ruotsalainen et al., 2019, p. 2).

Third, the notion of hybridity presumes a logical dependence that there was something "pure" before (Chadwick, 2013, pp. 14-15) that needs to be combined in a new blend, from which, in turn, a new hybrid would emerge. However, there has never been something like "pure journalism". This can be seen in the relation between journalism and business practices that are often more complex than theoretical principles of newswork and pure logics might suppose (Raviola, 2014). Similar phenomena can be observed when it comes to promotional news discourses (Erjavec, 2004), different values and norms (Porlezza \& Splendore, 2019), or different cultures (Mellado et al., 2017).

The notion of hybridity has been applied - although not exclusively - to various areas of contemporary journalism characterized by a strong reliance on digital technologies and practices or where forms of innovation take place on the terrain of "new" technologies entering the journalistic field. In particular, this has happened, in relation to data journalism, interactive journalism, forms of reporting influenced by either activist, hacktivist or hacker stances and automation and artificial intelligence. All these forms of journalism, although different in various regards, are characterized by an interplay between pure journalistic elements and others, non-journalistic ones. This introduction certainly doesn't aim at providing a full literature review about how the notion of "hybridity" has been used to analyze and define crossover typologies of journalism. Thus, the four aforementioned macroareas appear to be the most fruitful ones in terms of making sense of innovation and change in contemporary journalism. 
Starting from data journalism, Mark Coddington $(2014$, p. 337), in one of the most influential papers about computational journalism, pointed to this form of reporting's "cross-field hybridity" to highlight its relationships with the coding world and the open source culture in particular. Drawing on Chadwick's notion of "hybrid media system" (2013), instead, Alfred Hermida and Mary Lynn Young (2016, p. 59) have proposed a "hierarchy of hybrid" culture for Canadian journalism based on the encounters between older media logics and newer "data" logics. Their results show the existence of a "hierarchy of hybridity" among different media and based on the agency / power acquired thanks to the presence of technologists in the newsroom and the overall blending of journalism and technology.

The idea of blending between journalism and tech is at the core of various forms of reporting where hacker-journalists and their computational backgrounds play a major part in shaping new journalistic cultures and practices. Without explicitly referring to hybridity, Seth C. Lewis and Nikki Usher have explored an array of the areas where the encounter of journalists and technologists has brought to crossover forms of journalism: they indicated the "fusion of computer science and journalism", for instance, as the core of technologyfocused journalism innovation based on open source culture (Lewis \& Usher, 2013, p. 603) and have looked at the "Hacks/ Hackers" conference series as a case study to see how "the journalism and technology worlds came together" (Lewis \& Usher, 2014 , p. 384). Usher, instead, has looked at "interactive journalism" - a broader category that includes multimedia, immersive storytelling, data visualization, data-driven stories, explanatory graphics or other interactive features - as a terrain to look at in order to understand how practitioners with a coding background contribute in bringing new knowledge to the practice of journalism (Usher, 2016).

When it comes to activist, hacktivist or hacker stances influencing the journalistic field, instead, forms of hybridity - again in Chadwick's terms (2013) - have emerged in various contexts and Adrienne Russell (2016, p. 12) has offered some insights about how "hacker-activist or hacktivist sensibilities are gaining increased media capital across fields, including journalism, activism and government". This has been visible, in the journalistic field, especially on the level of the adoption of tools and software that are common among hackers and hacktivists for communication, security and organizing. Hackers, in particular, as it will be discussed in one of the articles included in this Thematic Section, have gained increased prominence in the journalistic field, as providers of technological solutions for information security or as sources.

"Combining human knowledge and expertise with the capabilities of machines to cope with an immense scale of data" is instead one of the instances where "hybridity" emerges in the relationship between journalism and artificial intelligence, according to Nicholas Diakopoulos (2019, p. 245). According to Diakopoulos, human-machine hybrid systems, such as those created by the interplay between algorithms or bots and human journalists, will have a decisive role in shaping journalism in the future, as more and more forms of artificial intelligence and machine learning come to support, enhance or even substitute human journalists in the making of various journalistic tasks.

This brief overview of how various interpretations of the notion of "hybridity" has been used in research about new forms of crossover journalism sets the stage for the contributions included in this Thematic Section of Studies in Communication Sciences (SComS). The Section aims at contributing to the analysis of the phenomenon of hybridity in journalism both by providing theoretical reflections about the conceptualization of "hybridity", and some case studies that look at particular aspects of hybridity. On the theoretical side, an interview with Andrew Chadwick, authored by Adrienne Russell, opens the Thematic Section and brings new insights about the evolution of the "hybrid media system" (Chadwick, 2013), particularly in light of recent global political turmoil 
and uncertainty. Christopher Buschow, instead, discusses practice theories as innovative ways of looking at empirical challenges in journalism studies, especially in regard to the journalistic production. Finally, Di Salvo and Porlezza, who are also the editors of this Thematic Section, discuss how hackers can become journalistic sources, forcing reporters to re-discuss their role, professional norms and practices, while dealing with controversial hybrid players.

As both this Introduction as well as the three papers in the Thematic Section show, hybridity is more than just a heuristic notion that allow us to go beyond a binary understanding of journalism. It goes beyond re-mixing genres, new blends of journalism and entertainment or activism, and collaborations between journalists, hackers, computer scientists, or even AI-driven tools. As Mast et al. (2017, p. 9) declare, hybridity "can be a fruitful concept to study from an interdisciplinary perspective the creative transformations, productive collaborations and innovative developments, witnessed in contemporary journalism, which is always 'in progress' or 'under construction'”. However, while the notion's deployment remains problematic given its multiple connotations, often loose meanings, and manifold normative associations, it definitely holds the power to challenge traditional understandings of journalism - which may be necessary if we want to capture and understand the increasing complexity of the journalistic field.

\section{References}

Baym, G. (2017). Journalism and the hybrid condition: Long-form television drama at the intersections of news and narrative. Journalism, 18(1), 11-26.

Chadwick, A. (2013). The hybrid media system: Politics and power. New York: Oxford University Press.

Coddington, M. (2014). Clarifying journalism's quantitative turn: A typology for evaluating data journalism, computational jour- nalism, and computer-assisted reporting. Digital Journalism, 3(3), 331-348.

Deuze, M., \&Witschge, T. (2018). Beyond journalism: Theorizing the transformation of journalism. Journalism, 19(2), 165-181.

Deuze, M., \& Witschge, T. (2020). Beyond journalism. Malden: Wiley.

Diakopoulos, N. (2019). Automating the news: How algorithms are rewriting the media. Cambridge: Harvard University Press.

Erjavec, K. (2004). Beyond advertising and journalism: Hybrid promotional news discourse. Discourse \& Society, 15(5), 553-578.

Hermida, A., \& Young, M. L. (2016). Finding the data unicorn: A hierarchy of hybridity in data and computational journalism. Digital Journalism, 5(2), 159-176.

Latour, B. (2013). An inquiry into modes of existence. Cambridge, MA: Harvard University Press.

Lewis, S. C., \& Usher, N. (2013). Open source and journalism: Toward new frameworks for imagining news innovation. Media, culture \& society, 35(5), 602-619.

Lewis, S. C., \& Usher, N. (2014). Code, collaboration, and the future of journalism: A case study of the Hacks/Hackers global network. Digital Journalism, 2(3), 383-393.

Mast, J., Coesemans, R., \& Temmerman, M. (2017). Hybridity and the news: Blending genres and interaction patterns in new forms of journalism. Journalism, 18(1), 3-10.

Mellado, C., Hellmueller, L., Márquez-Ramírez, M., Humanes, M. L., Sparks, C., Stepinska, A., ... Wang, H. (2017). The hybridization of journalistic cultures: A comparative study of journalistic role performance. Journal of Communication, 67(6), 944-967.

Milan, S. \& van der Velden, L. (2016). The alternative epistemologies of data activism. Digital Culture \& Society, 2(2), 57-74

Papacharissi, Z. (2015). Toward new journalism(s): Affective news, hybridity, and liminal spaces. Journalism Studies, 16(1), 27-40.

Porlezza, C. \& Splendore, S. (2019). From open journalism to closed data: Data journalism in Italy. Digital Journalism, 7(9), 1230-1252.

Raviola, E. (2014). We have never been pure: Negotiations between journalism and business in newspaper organizations. 
In J. Pallas, L. Strannegård, \& S. Jonsson (Eds.), Organizations and the media: Organizing in a mediatized world (pp. 96-115). London: Routledge.

Ruotsalainen, J., Hujanen, J., \& Villi, M. (2019). A future of journalism beyond the objectivity-dialogue divide? Hybridity in the news of entrepreneurial journalists. Journalism. Advance online publication. https://doi. org/10.1177/1464884919867216.

Russell, A. (2016). Journalism as activism: Recoding media power. Cambridge: Polity.

Stross, B. (1999). The hybrid metaphor: From biology to culture. Journal of American Folklore 112(445), 254-267.
Usher, N. (2016). Interactive journalism: Hackers, data, and code. Champaign, IL: University of Illinois Press.

Witschge, T., Anderson, C., Domingo, D., \& Hermida, A. (2019). Dealing with the mess (we made): Unraveling hybridity, normativity, and complexity in journalism studies. Journalism, 20(5), 651-659.

Zelizer, B. (2009). Introduction: Why journalism's changing faces matter. In B. Zelizer (Ed.), The changing faces of journalism: Tabloidization, technology and truthiness (pp. 1-10). New York: Routledge. 